\title{
Effectiveness of the female condom in preventing HIV and sexually transmitted infections: a systematic review and meta- analysis
}

Alison B. Wiyeh ${ }^{1,2^{*}}$ D, Ruth K. B. Mome ${ }^{3}$, Phetole W. Mahasha ${ }^{1,4}$, Eugene J. Kongnyuy ${ }^{5}$ and Charles S. Wiysonge ${ }^{1,6,7}$

\begin{abstract}
Background: The effectiveness of female condoms for preventing HIV and sexually transmitted infections (STIs) remains inconclusive. We examined the effects of female condoms on the acquisition of HIV and STIs.

Methods: We searched four databases, two trial registries, and reference lists of relevant publications in October 2018 and updated our search in February 2020. We screened search output, evaluated study eligibility, and extracted data in duplicate; resolving differences through discussion. We calculated the effective sample size of cluster randomised trials using an intra-cluster correlation coefficient of 0.03. Data from similar studies were combined in a meta-analysis. We performed a non-inferiority analysis of new condoms relative to marketed ones using a non-inferiority margin of 3\%. We assessed the certainty of evidence using GRADE.
\end{abstract}

Results: We included fifteen studies of 6921 women. We found that polyurethane female condoms (FC1) plus male condoms may be as effective as male condoms only in reducing HIV acquisition ( 1 trial, $n=149$ women, RR 0.07, $95 \% \mathrm{Cl}$ 0.00-1.38; low-certainty evidence). However, the use of FC1 plus male condoms is superior to male condoms alone in reducing the acquisition of gonorrhoea ( 2 trials, $n=790, R R \quad 0.59,95 \% \mathrm{Cl} 0.41-0.86$; high-certainty evidence) and chlamydia ( 2 trials, $n=790$, RR $0.67,95 \% \mathrm{Cl} 0.47-0.94$; high-certainty evidence). Adverse events and failure rates of FC1 were very low and decreased during follow up. Although the functionality of newer female condoms (Woman's, Cupid, Pheonurse, Velvet, and Reddy) may be non-inferior to FC2, there were no available studies assessing their efficacy in preventing HIV and STIs.

Conclusion: The use of female plus male condoms is more effective than use of male condoms only in preventing STIs and may be as effective as the male condom only in preventing HIV. There is a need for well conducted studies assessing the effects of newer female condoms on HIV and STIs.

PROSPERO registration number: CRD42018090710

Keywords: Female condom, HIV, Sexually transmitted infections, Systematic review

\footnotetext{
* Correspondence: wberiliy@yahoo.co.uk

'Cochrane South Africa, South African Medical Research Council, Cape Town, South Africa

${ }^{2}$ Department of Epidemiology, University of Washington School of Public Health, Seattle, Washington, USA

Full list of author information is available at the end of the article
}

(c) The Author(s). 2020 Open Access This article is licensed under a Creative Commons Attribution 4.0 International License, which permits use, sharing, adaptation, distribution and reproduction in any medium or format, as long as you give appropriate credit to the original author(s) and the source, provide a link to the Creative Commons licence, and indicate if changes were made. The images or other third party material in this article are included in the article's Creative Commons licence, unless indicated otherwise in a credit line to the material. If material is not included in the article's Creative Commons licence and your intended use is not permitted by statutory regulation or exceeds the permitted use, you will need to obtain permission directly from the copyright holder. To view a copy of this licence, visit http://creativecommons.org/licenses/by/4.0/ The Creative Commons Public Domain Dedication waiver (http://creativecommons.org/publicdomain/zero/1.0/) applies to the data made available in this article, unless otherwise stated in a credit line to the data. 


\section{Background}

The disease burden resulting from unsafe sex, including human immunodeficiency virus (HIV) infection and other sexually transmitted infections (STIs), has profoundly impacted the health of people in all parts of the world. Globally, it is estimated that 77.3 million people have been infected with HIV since the start of the HIV epidemic, with approximately half of those infected dying from AIDS related illnesses [1]. Although the incidence of HIV has shown a decrease over the last seventeen years, there were 1.8 million newly infected people in 2017 [1]. In subSaharan Africa, young women continue to lead in rates of new HIV infection with three in four new infections being amongst young girls aged $15-19$ years $[1,2]$. A vast majority of new HIV and STI infections in Sub-Saharan Africa occur through heterosexual transmission $[3,4]$. In many cases, STIs that go undiagnosed do not only lead to longterm complications such as infertility and cervical cancer but also enhance HIV susceptibility [5, 6]. Consistent condom use remains the most effective barrier against the sexual transmission of HIV. Male condoms have proven to be 80 to $90 \%$ effective $[7,8]$. Unfortunately, the subordinate status of women in many countries makes negotiating male condom use with partners especially difficult $[9,10]$. This makes women particularly vulnerable to HIV infection and other STIs like gonorrhoea, chlamydia, and syphilis. This warrants the need for alternative methods and effective female initiated methods for STI and HIV prevention.

The female condom is a female-initiated dual method of contraception. In 1993, the polyurethane condom also known as FC1 (Female Health Co., Chicago, IL, USA) became the first female condom to be approved by the United States Food and Drug Administration (USFDA) as a contraceptive and a method of protection against STIs, including HIV/AIDS [11]. It was replaced in 2009 by an identical second generation female condom FC2, which is made from synthetic latex and offers the advantage of having a reduced cost of production $[12,13]$. Currently, there are four female condoms that have been prequalified by the World Health Organization (WHO)/United Nations Population Fund (UNFPA). These include the Cupid, FC2, Velvet and the Woman's condom [14]. There are several others that are being developed and in process for UN and FDA approval with the aim of reducing cost and increasing acceptability $[15,16]$.

Despite variations in the designs of the different types of female condoms that are available, they share common components which include: an outer retention mechanism that prevents invagination, a sheath that lines the vagina, an internal retention mechanism that ensures the condom stays within the vagina and an insertion feature that facilitates insertion of the condom [17]. Current prequalification guidelines recommend that contraceptive efficacy studies be conducted for novel female condom designs that are not considered equivalent to an existing marketed female condom with an established efficacy rate [18]. However, for new female condoms whose design and specifications are sufficiently similar to those of a marketed device with a known efficacy rate established from a clinical effectiveness study, the clinical effectiveness of the new female condom can be established on the basis of a clinical study comparing the incidence of failures modes. Also, the manufacturer may use a device that has been evaluated directly against a device whose effectiveness is known and has been shown to be non-inferior in the event where there is no suitable marketed device available [18].

\section{Why it is important to do this review}

Although laboratory studies suggest that the female condom may be as effective as the male condom in preventing HIV and STIs [19], the evidence remains uncertain especially for the new generation female condoms. Several reviews that have examined the effectiveness of female condoms in preventing STIs and HIV found a limited number of randomized controlled trials [20,21]. Furthermore, these reviews are outdated and do not examine the functionality of the more recent designs of female condoms that are increasingly being manufactured to address the shortcomings of the older ones. Our review is timely considering the recent reclassification of the female condom from a class III device to a class II device in September 2018 by the USFDA [22]. This reclassification will simplify the regulatory process for the approval of newer female condoms, ensuring that women have more contraceptive options from which to choose. This move has the potential of increasing availability, access, acceptability and uptake of the female condom.

In this systematic review our primary aim was to examine the evidence around the effectiveness of the female condom on the prevention of HIV and other STIs among women. We also assess the functionality of new female condoms compared to the current widely marketed FC2 female condom.

\section{Methods \\ Criteria for considering studies for this review}

The methods used to conduct this systematic review are described in the published protocol [23]. We included randomised controlled trials (both individually and cluster randomised) in women engaged in heterosexual activity in any setting, with no clinical or laboratory-confirmed signs of STIs. Included trials compared the female condom with placebo, or other barrier methods for HIV and/or STI prevention. Our outcomes of interest were the Incidence of HIV, and the Incidence of STIs (including but not limited to chlamydia, gonorrhoea, syphilis, herpes simplex virus, trichomoniasis, Lymphogranuloma venereum, HPV, bacterial vaginosis) and adverse events. We had aimed to 
assess the effectiveness of the newer female condoms in preventing HIV and other STIs. However, we did not find any published or unpublished studies that assessed this outcome. Available studies mostly assessed the functionality of new types of female condoms, hence we synthesized the evidence around the functionality of these condoms by assessing the condom clinical failure rates as defined by Beksinska et al. 2007 [24]. We included trials in which the FC1 or FC2 were compared top each other, or compared to any other marketed female condoms.

\section{Search methods for identification of studies}

Using a comprehensive search strategy, we searched PubMed, Cochrane Central Register of Controlled Trials (CENTRAL) and EMBASE on the 9 October 2018 with no restrictions. Our search strategy was updated in February 2020. We used the terms 'female condom', 'HIV', and 'sexually transmitted diseases'. Details of our search terms can be found in the published protocol. We also searched the reference lists of previous reviews [20, 21], as well as articles included in this review for relevant studies we may have missed through the electronic search of peer-reviewed literature. We searched the WHO International Clinical Trials Registry Platform (ICTRP) and ClinicalTrials.gov for ongoing trials. All identified records were deduplicated using Mendeley reference management software.

\section{Study selection}

Two authors (RKB and EJK, RKB and CSW or AW and PM) independently screened the titles and abstracts obtained from the electronic searches, as well as the full text of all potentially eligible studies for relevance using a standardised eligibility form with predefined inclusion criteria. Disagreements between the authors who assessed study eligibility were resolved by discussion and consensus. Following the eligibility assessment, we classified all studies that met our inclusion criteria as included. Studies that met the design, intervention and participant inclusion criteria but with relevant outcomes not yet available were classified as ongoing (if the study was not yet completed) or awaiting assessment (if the study was completed but the data not yet published and we could not get any relevant outcome data from trial investigators). We excluded studies that did not meet our inclusion criteria and stated the reasons for exclusion.

\section{Data extraction and management}

Two authors independently extracted data using a standardised data extraction form and performed risk of bias assessment. Extracted information included the study details, participant details, intervention details and outcome details. We assessed the risk of bias for RCTs using the Cochrane risk of bias tool for randomized controlled trials as described in the Cochrane Handbook for Systematic Reviews of Interventions [25]. For crossover and cluster RCTs, we assessed for risk of bias specific to these study designs as described in the Cochrane Handbook for Systematic Reviews of Interventions [25]. Disagreements between the authors who extracted data and assessed risk of bias were resolved by discussion and consensus. We planned to asses for publication bias using a funnel plot, but this was not done due to the insufficient number of studies reporting the various outcome measures. Data were entered into Review Manager 5.3 (RevMan 5.3) software and checked for accuracy.

Dichotomous data were presented and compared using risk ratios with $95 \%$ confidence intervals. We assessed heterogeneity between trial results by visually inspecting the forest plots for overlapping of confidence intervals, followed by the chi-squared test of homogeneity (with significance defined at an alpha level of $10 \%)$. We then used the $\mathrm{I}^{2}$ test to quantify the degree of heterogeneity. We analysed the data using RevMan 5.3 and Excel statistical software. We conducted meta-analysis when included studies were similar in terms of participants, interventions, and outcomes. We pooled the study results using the Mantel-Haenszel method and the fixed model effects. When there was substantial heterogeneity, we used the random-effects model. When the $\mathrm{I}^{2}$ was greater than $50 \%$, we considered it to be substantial heterogeneity and explored the cause of heterogeneity using subgroup analyses. When the studies were not similar enoiugh to be metaanalysed, we narratively synthesised the evidence.

For cluster randomised trials, we reduced each trial to its effective sample size by dividing its original sample by the design effect; where the design effect equals $1+(\mathrm{M}-$ 1) * ICC (Higgins 2011). M is the average cluster size and ICC is the intracluster correlation coefficient. We used an ICC of 0.03 which was reported by one of the included studies. Finally, we assessed the quality of the evidence using the Grading of Recommendations, Assessment, Development and Evaluations (GRADE) approach, as outlined in the GRADE handbook [26].

In order to assess non inferiority of new female condoms to widely marketed ones, we used the WHO/ UNFPA guidelines for female condom generic specification, prequalification and procurement [18]. As stated in this guideline, included studies were required to have a minimum of 200 women, with at least 5 uses of each condom type. Non inferiority was demonstrated by calculating the difference of total clinical failure rates between the new female condom and the marketed one. The upper bound of the one-sided 95\% confidence interval of this difference was expected to be less than $3 \%$ for non-inferiority [18]. We conducted both per protocol and intention to treat analysis for all relevant trials using random effects model [27]. 


\section{Results}

Figure 1 summarises our search and selection process. We identified 2325 records during our initial search in 2018. An updated search in 2020 identified 121 new records. We screened 1948 titles and abstracts after removing duplicates. Thirty-one records met our inclusion criteria. Following full text assessment, independent review and discussion of the thirty-one full-text articles, we included fifteen studies published in eighteen articles.

We searched clinicaltrials.gov and the WHO ICTRP and found 4 relevant trial records. Two trials had no comparator arms, the results from one trial had been published and included amongst the included trials, and the results of one completed crossover trial posted in 2010 in which the Program for Appropriate Technology in Health (PATH) Woman's Condom and the FC2 Female Condom were compared could not be found [28].

\section{Included studies}

\section{Study designs}

The study designs include: Two cluster randomised trials $[29,30]$, ten crossover trials including three noninferiority trials [31-39], and three randomized controlled trials $[40,41]$. See Table 1.

\section{Participants}

The number of participants in each study ranged from 55 to 1929 women over 15 years old. The fifteen studies included a total of 6921 women. Accounting for the design effect in the two cluster-randomised trials with 2477 participants (using an intra-cluster correlation coefficient of 0.03 reported by one of them) their combined effective sample size becomes 790 participants.

The included studies were mostly conducted in women in low-income and middle-income countries: South Africa $(n=5)$, China $(n=1)$, China and South Africa $(n=1)$, Thailand $(n=1)$, Kenya $(n=1)$, Zimbabwe $(n=1)$ and Brazil $(n=1)$. In one study (an abstract), the authors did not mention the country where the study was conducted [46]. Three trials were conducted in high income setting, all in the USA. The women in these studies included both those considered to have a high risk of HIV/STI transmission such as female sex workers, and women in monogamous relationships judged as having a low risk. See Table 1.

\section{Interventions}

Four trials compared the polyurethane female condom (FC1) plus male condom to the male condom only. In

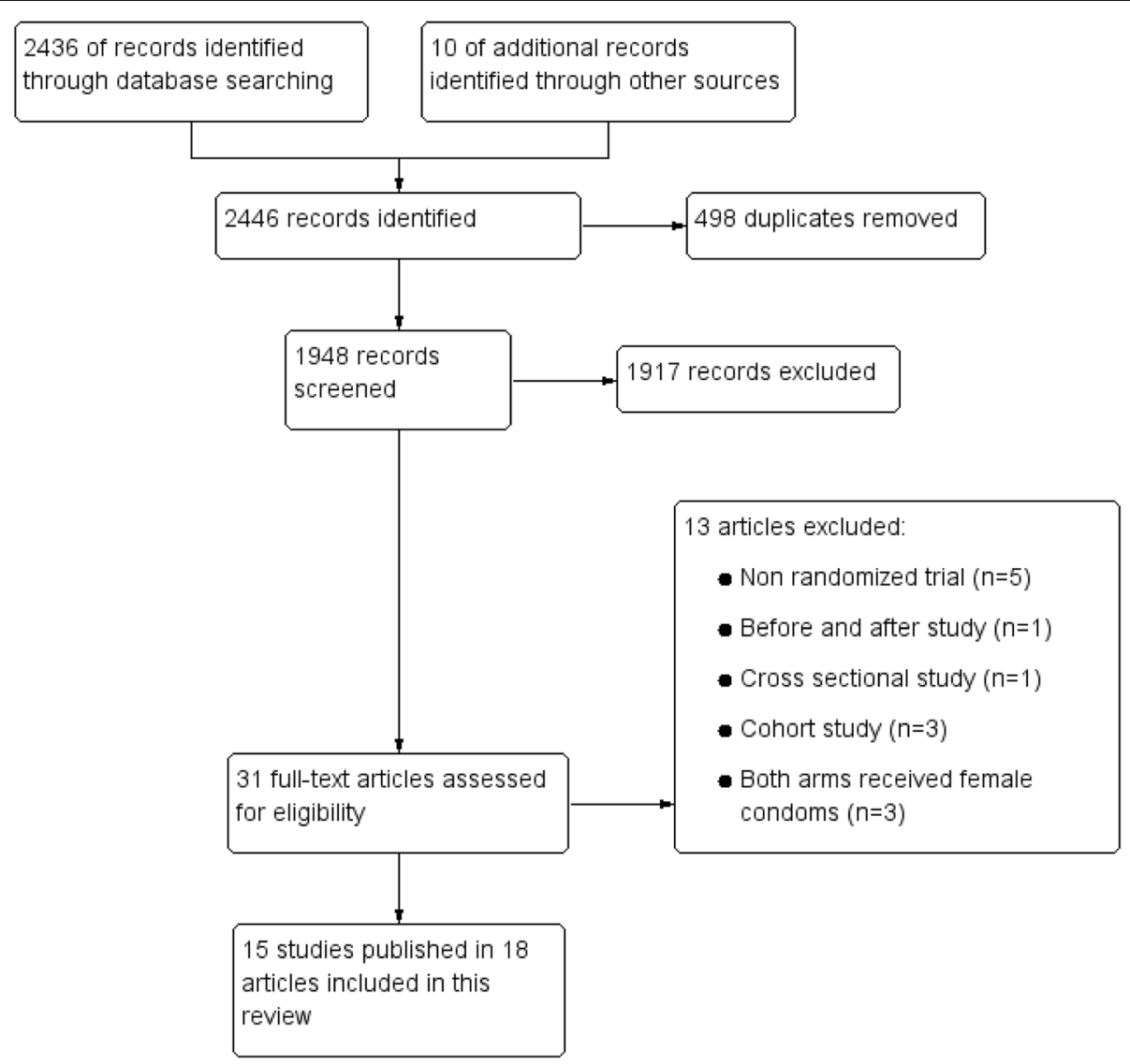

Fig. 1 Study flow diagram 


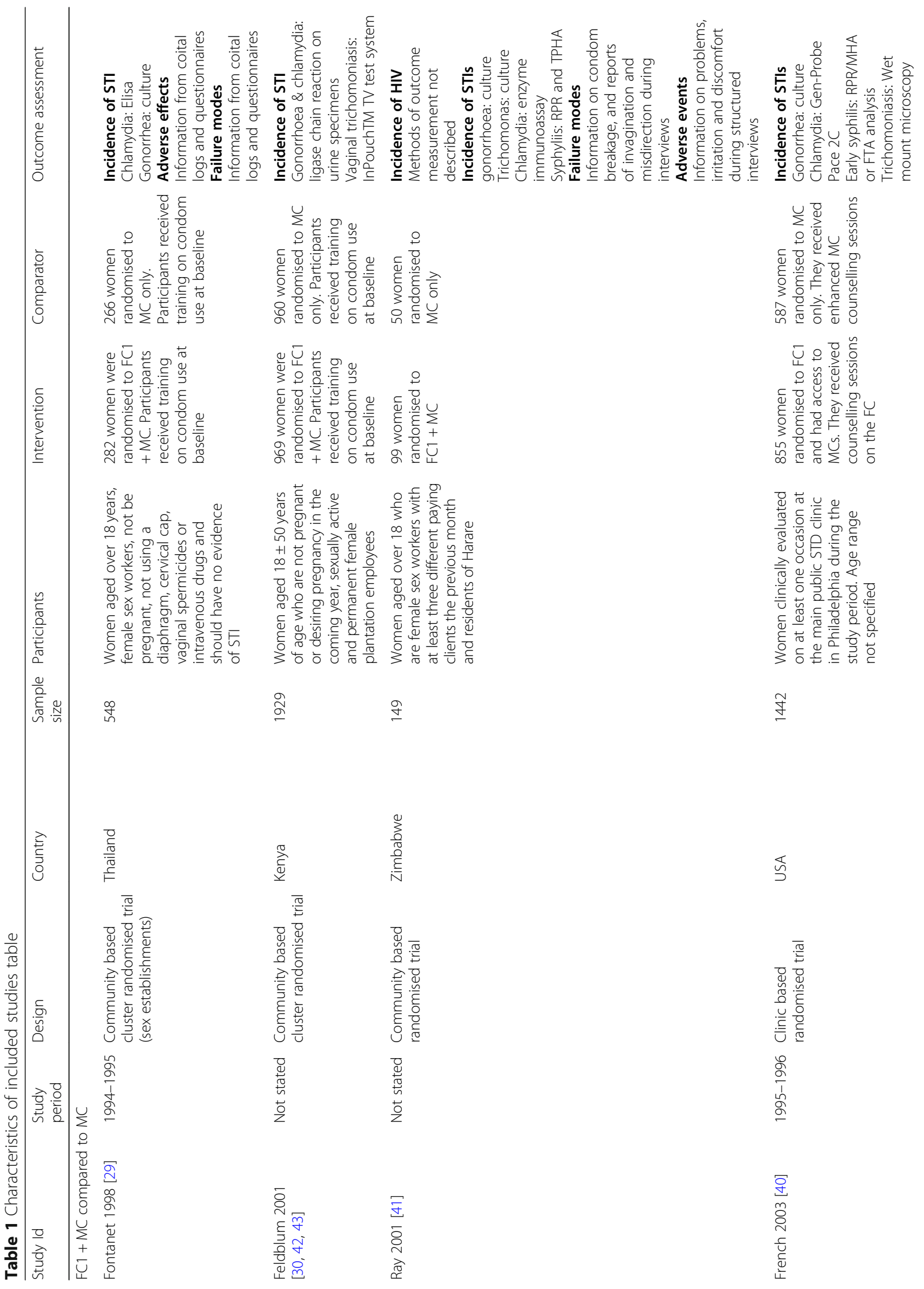




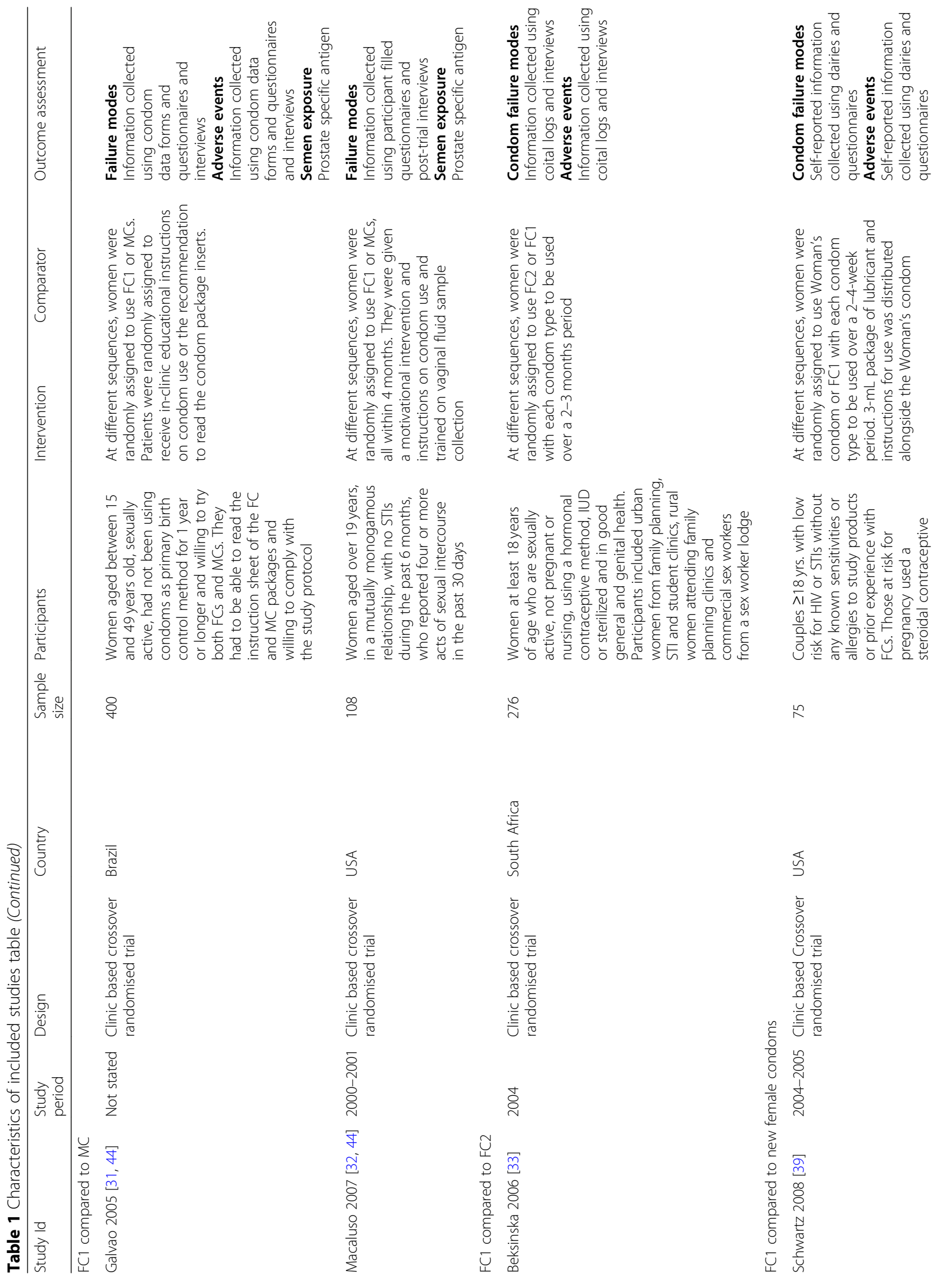




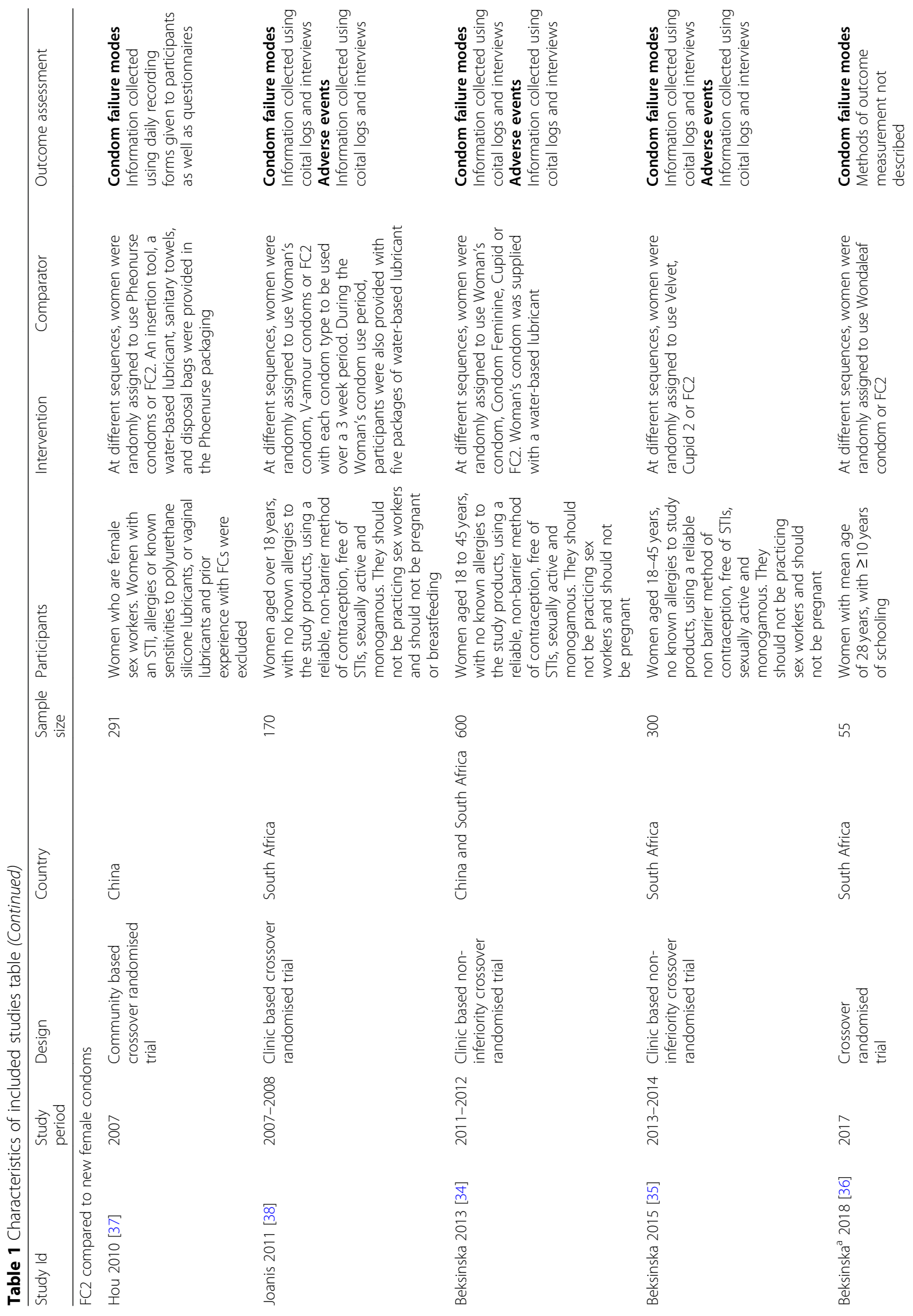




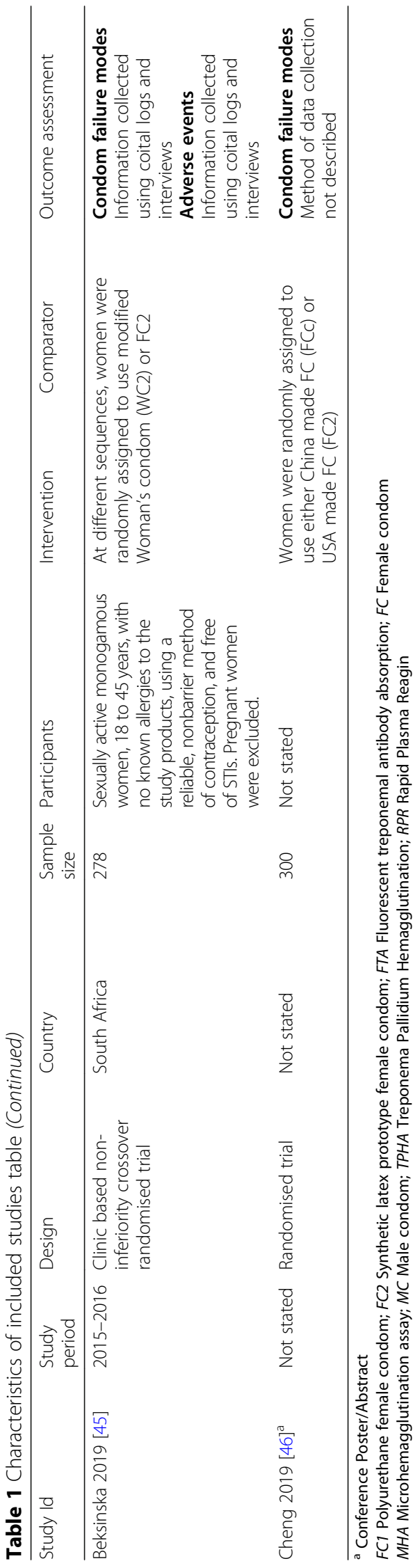


three trials, participants in the intervention group were given a combination of FC1 and male condoms [29, 30, 41 , In the fourth trial, the women in the intervention group were given FC1 and had access to male condoms [40]. Two crossover studies compared the female condom to the male condom. At different sequences, women were randomly assigned to use FC1 or male condoms [31, 32]. The focus of these two studies was mainly to assess mechanical problems and semen exposure while using female condoms.

In eight crossover trials, the functionality of new female condoms was compared against widely marketed ones; one trial compared FC2 to FC1 [33], the Woman's condom was compared to the FC1 in one trial and in seven trials the FC2 was compared to new female condoms. More information is provided in Table 1.

\section{Outcomes}

The main outcomes reported in studies that compared the female plus male condom to the male condom only were incidence of STI, mechanical problems and adverse events. Only one study reported on the effect of female plus male condoms on HIV transmission [41]. In two studies, semen exposure was measured using prostate specific antigen [31, 47].

Amongst studies that compared the functionality of new female condoms against widely marketed ones, female condom failure modes were the main outcomes reported. The failure modes reported were breakage, slippage, misdirection, invagination, total clinical failure and total failure rates.

\section{Excluded studies}

We excluded eleven articles for the following reasons: non randomized trial $(n=5)$ [47-51], before and after study $(n=1)$ [52], cross sectional study $(n=1)$ [53], cohort study $(n=3)$ [54-56], both arms received female condoms and it was not the main intervention $(n=3)$ [42-44]. See Fig. 1.

\section{Risk of bias in included studies}

We assessed the included studies for selection bias. One study assigned participants to intervention arm based on the week of initial visit and this was scored as high risk for random sequence generation and unclear risk for allocation concealment [40]. Three studies failed to provide sufficient information and were scored as having unclear risk of bias for both random sequence generation and concealment [31, 36]. Three studies reported adequately on the methods of random sequence generation but failed to report on allocation concealment and were scored as having unclear risk of bias for allocation concealment [29, 30, 37]. The rest of the studies adequately reported random sequence generation and allocation concealment and were judged to have low risk of bias for both domains.

With regards to blinding, it was generally difficult to blind the participants and to some extent the research personnel due to the nature of the female condom. All studies had unclear risk of bias for blinding of participants and personnel. All except one study had unclear risk of bias for blinding of outcome assessors [40].

There was high risk of attrition bias in three studies; Macaluso 2007 reported attrition rates of $42 \%$ [32] In the study by French 2003 , only $50 \cdot 2 \%$ of the female/male condom arm and $51.1 \%$ of the male condom only arm completed at least one visit [40]. Fontanet 1998 reported that forty-four women had no follow-up at all, 11 (4.3\%) from the male condom group, and $33(11.7 \%)$ from the male/female condom group. Almost half of the study participants were lost to follow-up after 3 months [29]. Six studies were judged as having low attrition rates [30, $34,35,38,39,45]$ and the rest were rated as unclear. Three studies were rated as having low risk of reporting bias, with the rest providing insufficient information to enable judgement, hence judged to have unclear risk of bias.

\section{Other potential sources of bias}

In four studies, the authors reported support from companies that manufacture female condoms including; Chartex international $[29,41]$, the Female Health Company [40], and Cupid Ltd. [35] The support included free condom supplies in one study and funding in three studies and both condom supplies and funding in one study. Details about how potential conflicts of interest were handled are not described. We rated these studies as having unclear risk of bias due to lack of enough information to make a definitive judgement. Two studies did not provide information regarding funding and were also considered to have unclear risk of bias. We had planned to assess for publication bias using a funnel plot. This was not done due to the small number of studies.

In cross-over trials, participants randomly receive a sequence of different treatments. These trials are prone to carryover bias which occurs when participants are switched from one intervention to another without an adequate washout period in-between. Due to the nature of the intervention in this review, we judged the potential for carryover bias to be low. We have summarised the risk of bias in included studies in Table 2 .

\section{Effects of female condoms on HIV and other STIs Comparison of the female (plus male) condom to the male condom only}

All studies included in this comparison used the polyurethane female condom also known as the FC1. 
Table 2 Summary of risk of bias in included studies

\begin{tabular}{|c|c|c|c|c|c|c|c|c|c|c|c|c|c|c|c|}
\hline Domain & \begin{tabular}{|c|} 
Beksinska \\
2006 \\
\end{tabular} & $\begin{array}{c}\text { Beksinska } \\
2013\end{array}$ & \begin{tabular}{|c|} 
Beksinska \\
2015 \\
\end{tabular} & $\begin{array}{c}\text { Beksinska } \\
2018 \\
\end{array}$ & $\begin{array}{l}\text { Feldblum } \\
2001\end{array}$ & $\begin{array}{c}\begin{array}{c}\text { Fontanet } \\
1998\end{array} \\
\end{array}$ & \begin{tabular}{c|}
$\begin{array}{c}\text { French } \\
2003\end{array}$ \\
\end{tabular} & \begin{tabular}{c|} 
Galvao \\
2005 \\
\end{tabular} & \begin{tabular}{|c|} 
Hou \\
2010 \\
\end{tabular} & $\begin{array}{c}\text { Joanis } \\
2011\end{array}$ & $\begin{array}{c}\text { Macaluso } \\
2007\end{array}$ & \begin{tabular}{|c|} 
Ray \\
2001
\end{tabular} & $\begin{array}{l}\text { Schwartz } \\
2008 \\
\end{array}$ & \begin{tabular}{|l} 
Beksinksa \\
2019 \\
\end{tabular} & \begin{tabular}{|c|} 
Cheng \\
2019 \\
\end{tabular} \\
\hline $\begin{array}{l}\text { Random sequence } \\
\text { generation (selection bias) }\end{array}$ & $\odot$ & $\odot$ & $\odot$ & $?$ & $\odot$ & $\odot$ & $\ominus$ & $?$ & $\odot$ & $\odot$ & $\odot$ & $\odot$ & $\odot$ & 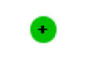 & $?$ \\
\hline $\begin{array}{l}\text { Allocation concealment } \\
\text { (selection bias) }\end{array}$ & $\odot$ & $\odot$ & $\odot$ & $?$ & $?$ & $?$ & $?$ & $?$ & $?$ & $\odot$ & $\odot$ & $\odot$ & $\odot$ & $\odot$ & $?$ \\
\hline $\begin{array}{c}\text { Blinding of participants and } \\
\text { personel (performance } \\
\text { bias) }\end{array}$ & $?$ & $?$ & $?$ & $?$ & $?$ & $?$ & $?$ & ? & $?$ & $?$ & $?$ & $?$ & $?$ & $?$ & $?$ \\
\hline $\begin{array}{l}\text { Blinding of outcome } \\
\text { assessment (detection bias) }\end{array}$ & $?$ & $?$ & $?$ & $?$ & $?$ & $?$ & (†) & $?$ & $?$ & $?$ & $?$ & $?$ & $?$ & $?$ & $?$ \\
\hline $\begin{array}{c}\text { Incomplete outcome data } \\
\text { (attrition bias) }\end{array}$ & $?$ & (4) & + & $?$ & ( & $\theta$ & $\theta$ & $?$ & $?$ & (†) & $\theta$ & $?$ & + & + & $?$ \\
\hline $\begin{array}{l}\text { Selective reporting } \\
\text { (reporting bias) }\end{array}$ & $?$ & $\odot$ & $\odot$ & $?$ & $\odot$ & $?$ & $?$ & $?$ & $?$ & $?$ & $?$ & $?$ & $?$ & $\odot$ & $?$ \\
\hline Other bias & $\odot$ & $\odot$ & $?$ & $?$ & $\odot$ & $?$ & $?$ & $\odot$ & $?$ & 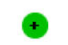 & $\odot$ & $?$ & $\odot$ & $\odot$ & $?$ \\
\hline
\end{tabular}

Low risk, High risk, Unclear risk.

\section{Incidence of HIV}

One study including 149 participants compared the effect of the female plus male condom to the male condom only on the incidence of HIV infection [41]. This was a randomized controlled trial conducted in Zimbabwe amongst female sex workers. During the study, no woman in the female plus male condom group became HIV infected, while three women became HIV positive in the male condom only group. However this difference was not statistically significant (RR 0.07, 95\% CI 0.00 to 1.38 ).

\section{Incidence of STls}

Four studies that compared the female plus male condom to the male condom, reported on this outcome [29, $30,40,41]$. Three of these studies compared the female plus male condom to the male condom only [29, 30, 41] and one compared the female condom alone to the male condom though the authors report that over one third of the women in the female condom group had access to and used the male condom [40]. Three of these trials, including 2232 women reported this outcome in a manner that was similar enough to be combined.

As seen in Fig. 2, the use of the female plus male condom significantly reduces the risk of any STI when compared to male condom only (RR $0.74,95 \%$ CI 0.62 to $\left.0.89 ; \mathrm{I}^{2}=23 \%\right)$. When the data were disaggregated, the use of female plus male condoms compared to male condoms only significantly reduced the risk of gonorrhoea ( 2 trials, $n=790$ participants, RR $0.59,95 \% \mathrm{CI}$ 0.41 to 0.86 ) and chlamydia (2 trials with 790 participants, RR $0.67,95 \% \mathrm{CI} 0.47$ to 0.94 ). The pooled effect estimate was not significant for trichomoniasis (2 trials with 790 participants, RR 1.01, 95\%CI 0.63 to $1.60)$ and genital ulcer disease ( 1 trial with 475 participants, RR $4.7295 \%$ CI 0.23 to 97.87 ).

\section{Adverse events and condom failure}

Three studies reported adverse events. Ray 2001 found that $14 \%$ of the participants reported problems, irritation or discomfort with the use of the female condom [41]. Fontanet 1998 reported that the female condom was well tolerated, with no reports of genital lesions that could be attributed to the use of the female condom [29]. Galvao 2005 evaluated the frequency of selfreported acceptability problems. These included nonmenstrual vaginal bleeding during intercourse, pain or discomfort felt by either the male or the female partner and noise made by the condom during use. The frequency of acceptability problems was higher in the female condom group [31].

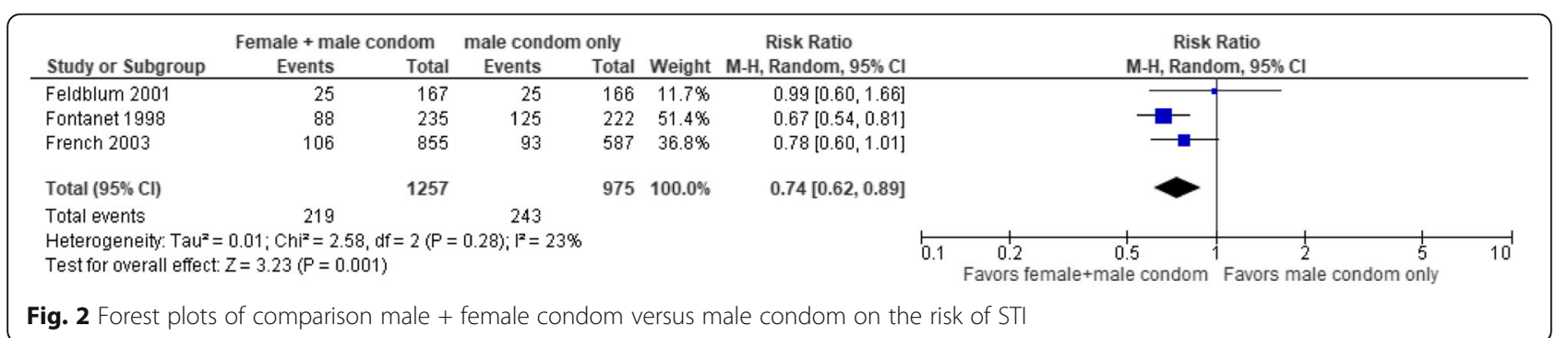


None of the six included studies that compared the male to the female condom reported on the total clinical failure rates or total condom failure rates. However, four studies reported on at least one of the four categories of failure: breakage, invagination, misdirection and slippage. Due to heterogeneity in the reporting of condom failure modes between the included studies, the findings could not be meta-analysed. Two studies reported on breakage; Fontanet 1998 and colleagues reported that male condoms tore more often than female condoms $(2.8 \%$ compared to 0.5\%) [29]. Similarly Macaluso 2007 found that when compared to the male condom, the female condom had lesser reported cases of breakage $(0.3 \%$ vs 1.3\%) [32]. With regards to slippage, both Fontanet 1998 and Macaluso 2007 found that slippage rates during use were higher for the female condom than the male condom: $5.7 \%$ versus $1.3 \%$ and $10.6 \%$ vs 2.1 for complete slippage, $2.6 \%$ for partial slippage $\geq 1 \mathrm{in}$. and $1.7 \%$ for partial slippage $\leq 1$ in. respectively [29, 32]. The authors further highlight that the proportion of female condoms slipping in or out decreased during follow up visits. Two studies found that the rates of invagination for the female condom were generally low. Ray 2001 reported invagination in 3.4\% of cases and Macaluso 2007 reported a rate of $3 \%$ [32, 41]. Three studies reported on misdirection, which was generally low. Fontanet 1998 and Ray 2001 each reported misdirection in 3.0\% of cases amongst those who used the female condom and Macaluso 2007 reported a rate of $5 \cdot 6 \%$ [29, 32, 41]. Galvao 2005 compared the rates of mechanical problems between the male and female condom groups [31]. Male condom mechanical problems were grouped together and included breakage during intercourse, total or partial slippage either during intercourse or during withdrawal and semen leakage on the woman's body. Female condom mechanical problems were equally grouped together and included; breakage during intercourse, slippage, misdirection, invagination, semen leakage onto the woman's body, condom clung to penis, moving with it during intercourse and problems encountered by the participants with the inner ring during intercourse. In this study, female condoms had significantly higher rates of self-reported mechanical problems than male condoms ( $20 \%$ vs $12 \%)$. For each condom type, women who received in-clinic educational instructions on the female and male condoms reported lesser mechanical problems compared with those who had to read the condom package inserts (FC: $6 \%$ vs $14 \%$ and MC: $4 \%$ vs $8 \%$ ).

\section{Functionality studies}

\section{Comparison of the FC2 to the FC1}

One crossover trial conducted in Durban South Africa and including 276 women, compared the functionality of FC2 to FC1 [33]. Each study participant was required to use ten of each condom type with their partners within a 2 to 3 month study period. Approximately one quarter of the study participants were lost to follow up during the study. Functionality measures assessed were breakage (clinical, nonclinical and total), incorrect penetration, outer ring displacement (partial, complete and total), and slippage (partial and complete). Though twice as many women reported incorrect penetration with FC1 than FC2, there was no statistically significant difference in the total clinical failure rates between both condoms (RR $0.81,95 \%$ CI 0.61 to 1.08). The number of participants reporting discomfort and adverse events including; discomfort during and after insertion, pain after insertion before sex, pressure causing urge for micturition, discomfort during sex, device uncomfortable to use and bleeding were similar in both groups. There was a non-significant excess number of cases of burning/rash or itching in the FC2 group (RR 11.00, 95\% CI 0.61 to 198.83). The effect on HIV incidence is not reported. One case of STI, presenting as a white discharge and confirmed using syndromic management was reported in the FC1 group (RR $0.3395 \%$ CI 0.01 to 8.18) [33].

Though the authors did not state that this was a noninferiority trial, it was powered enough to establish non inferiority. The difference of the total clinical failure rates of the $\mathrm{FC} 2$ compared to $\mathrm{FC} 1$ met the criteria for non-inferiority when we used both per protocol and Intention to treat analysis (RD $-0.01,95 \% \mathrm{CI}-0.02$ to $0 \cdot 00)$.

\section{Comparison of new female condoms to the FC2 and the FC1}

One study including 75 women compared the FC1 to the Woman's condom [39] and seven studies including 1994 women compared the FC2 condom to other types of female condoms [34-38, 45, 46]. The Woman's condom resulted, in non-significantly lower rates of total clinical failure (RR $0.7295 \%$ CI 0.51 to 1.02 ) when compared to the FC1. However, there was a significantly lower rates of total condom failure (RR 0.74 95\% CI 0.59 to 0.93 ) and adverse events (RR 0.28 95\% CI 0.17 to $0 \cdot 46)$. In addition to the standardised definition of failure modes [24], the author's definition of clinical failure rates in this trial includes other measures such as the partial turning inside out of the female condom as their measures of female condom performance were adapted from those of the male condom $[39,57]$. This study was not powered enough to establish non-inferiority.

When we considered the seven studies that compared the new female condoms to the $\mathrm{FC} 2$, there was no significant difference in the total clinical failure rates when the cupid/cupid 2 condoms ( 2 trials, $n=900$, RR 1.22 95\% CI 0.98 to 1.52 ) [34, 35], Velvet condom (1 trial, $n=300$, RR $0.9095 \%$ CI 0.63 to 1.29) [35], Woman's 
condom/Woman's condom 2 ( 3 trials, $n=1058$, RR 0.84 $95 \%$ CI 0.68 to 1.04 ) [34, 38, 45], Reddy female condom ( 2 trials, $n=770$, RR $0.8595 \%$ CI 0.65 to 1.11 ) [34, 38], and Pheonurse ( 1 trial, $n=291$, RR $1.0095 \%$ CI 0.92 to 1.08) [37] were compared to the FC2. One conference abstract for a trial comparing the Wondaleaf condom to the FC2 reported total clinical failure rates of $5.3 \%$ and $7.5 \%$ respectively [36]. Another abstract describing a study in which the functionality of the China female condom (FCc) was compared to the FC2 reported total clinical failure rates of 0.9 and $1.1 \%$ for the $\mathrm{FCc}$ and the FC2 respectively [46]. The difference in total clinical failure rates was deemed non-significant. The full text of this article was unavailable. We examine the risk difference and found that the functionality of the cupid, cupid, Velvet condom, Woman's condom, Reddy and phoenurse may be non-inferior to the FC2 based on the clinical failure rates, without any differences observed in per protocol and intention to treat analysis (see Fig. 3). The trial comparing the Wondaleaf condom to FC2 was not powered enough to demonstrate non-inferiority.

Four studies compared the total condom failure rate between the FC2 and other types of female condoms. There was no significant difference in total female condom failure rates when the Cupid/Cupid2 condoms (2 trials, $n=900$, RR $1.1695 \%$ CI 0.96 to 1.40$)$ [34, 35], Velvet condom ( 1 trial, $n=300$, RR $0.8895 \%$ CI 0.66 to $1 \cdot 18$ ) [35], Woman's condom ( 2 trials, $n=878$, RR 0.84 95\% CI 0.49 to 1.46$)$ [34, 45], Reddy female condom (1 trial, $n=600$, RR $0.8795 \%$ CI 0.65 to 1.15 ) [34] were compared to the FC2. None of the studies that compared the new female condoms to the $\mathrm{FC} 2$ assessed their direct effects on the incidence of HIV infection or STIs.

\section{Discussion}

Summary of the main results

In this review, we aimed to assess the effects of the female condom in preventing HIV and other STIs among women. Available evidence suggest that there may be no difference in the incidence of HIV infection when women used the polyurethane female condom plus the male condom compared to those who used the male condom only. However, female plus male condom reduces the risk of gonorrhoea and chlamydia and probably reduces the risk of trichomonas and other STIs when compared to the male condom only. Adverse events associated with use of the female condom were generally few and not life threatening. Condom breakage was more frequently reported amongst users of the male condom and slippage amongst users of the female condom. The rates of invagination and misdirection of the female condom were low ranging from 3 to $3.4 \%$ and $3-$ $5.6 \%$ respectively.

We note however that there were no eligible studies assessing the effectiveness of the new female condoms in preventing HIV and STIs. Available studies assessed the functionality of these new condoms against existing ones for the purpose of prequalification.

One study comparing the functionality of the FC2 to the FC1 found it to be non-inferior. The cupid, cupid 2,

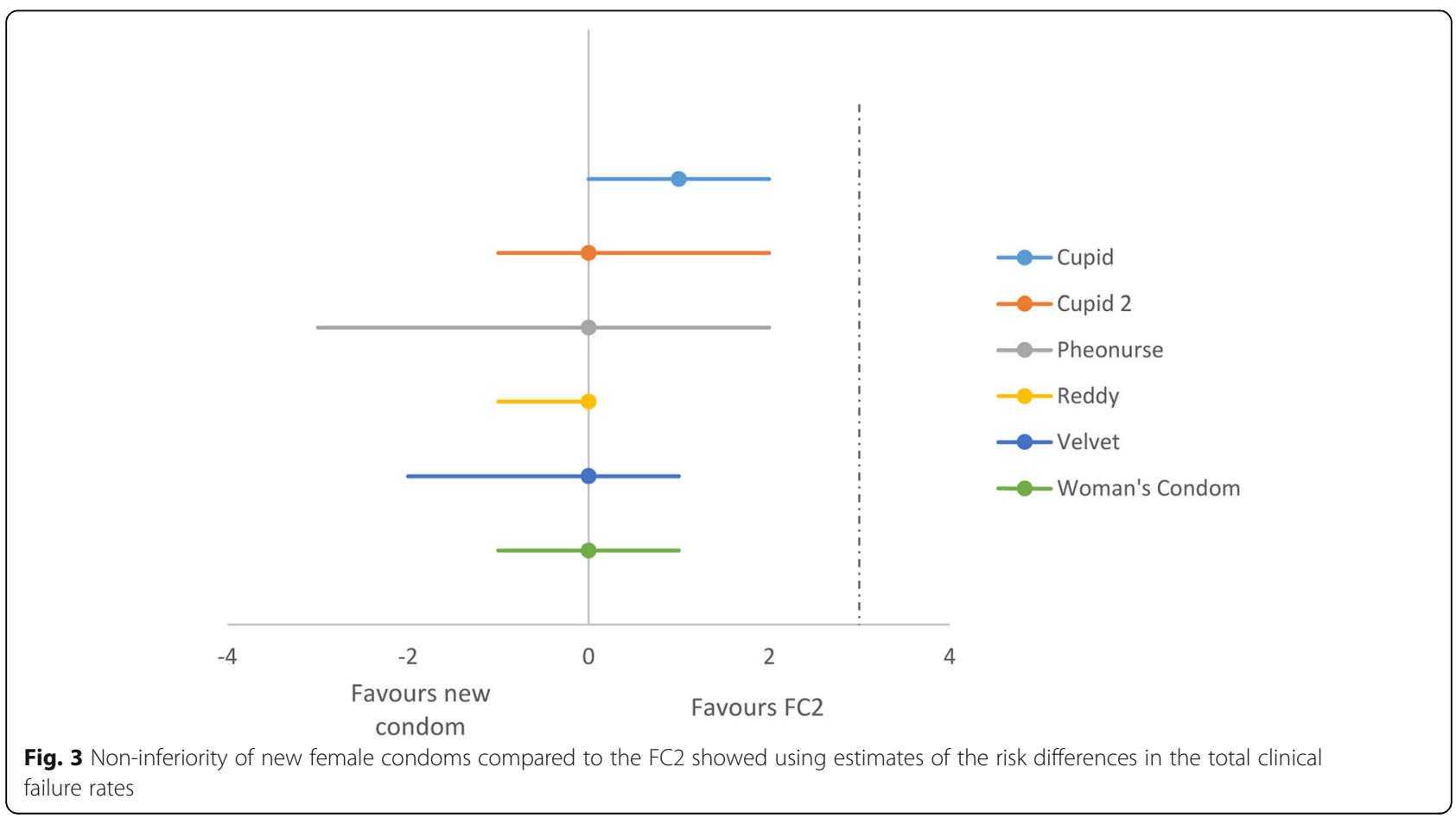


Velvet, Woman's, Reddy and Pheonurse, condoms were non-inferior to the FC2 based on their total clinical failure rates. Functionality studies which are often required for prequalification showed that FC2 was equivalent to FC1 based on non-clinical and functionality data, hence a full contraceptive efficacy study on FC2 was not necessary. However, this may not be the case for many of the new types of female condoms which, warranting the need for contraceptive efficacy studies.

Data from self-reports show that the usage of the female condom was generally poor in the intervention arms. French et al. in a sub study found that male condoms accounted for one third of the condom protected sex acts in the female condom group [40]. Feldblum et al. also highlight that though female condom distribution increased in the female plus male condom group, 39 and $58 \%$ of the women reported never using the female condom at 6 months and 12 month follow up visits [29]. Fontanet 1998 instructed women to use the female condom as a backup when clients refused to use male condoms and the use of the female condom remained limited, accounting for only $12 \%$ of all sexual acts [29]. Ray found that though the proportion of women in the female + male condom group who consistently used the male condom increased, only 3-9\% of women reported consistently using the female condom with clients during the study [41]. This further highlights the importance of high-quality studies assessing the acceptability of female condoms in the targeted populations.

\section{Certainty of the evidence}

The strength of this review lies in our adherence to the standardised guidelines on the conduct and reporting of systematic reviews [25]. We used the GRADE approach to assess the certainty of the evidence as shown in the summary of findings table 3 [26]. We judged the quality of evidence for FC1 plus male condoms compared to male condoms only as low and moderate in reducing the risk of HIV and STIs respectively. The certainty of the evidence was downgraded for very severe imprecision in the case of HIV and high risk of bias in the case of STIs. We rated the certainty of the evidence for the effect of FC1 plus male condom in preventing gonorrhoea and chlamydia as high. The effects of the FC1 plus male condom in preventing genital ulcer disease and trichomoniasis were rated as moderate. In both instance, we downgraded for severe imprecision.

Table 3 Summary of findings table Female condom + male condom compared to Male condom only for prevention of HIV an STIS Patient or population: prevention of HIV an STIs Intervention: Female condom + male condom Comparison: Male condom only

\begin{tabular}{|c|c|c|c|c|c|}
\hline \multirow{2}{*}{$\begin{array}{l}\text { Outcome № of } \\
\text { participants } \\
\text { (studies) }\end{array}$} & \multirow{2}{*}{$\begin{array}{l}\text { Relative effect } \\
(95 \% \mathrm{Cl})\end{array}$} & \multicolumn{3}{|c|}{ Anticipated absolute effects (95\% Cl) } & \multirow[t]{2}{*}{ Certainty } \\
\hline & & & & Difference & \\
\hline $\begin{array}{l}\text { HIV infection } \\
\text { № of participants: } 149 \\
\text { (1 RCT) }\end{array}$ & $\begin{array}{l}\text { RR } 0.07 \\
\text { (0.00 to } 1.38)\end{array}$ & $6.0 \%$ & $\begin{array}{l}0.4 \% \\
(0 \text { to } 8.3)\end{array}$ & $\begin{array}{l}5.6 \% \text { fewer } \\
\text { ( } 6 \text { fewer to } 2.3 \text { more) }\end{array}$ & $\begin{array}{l}\oplus \oplus \mathrm{OO}^{\mathrm{a}} \\
\mathrm{LOW}^{\mathrm{a}}\end{array}$ \\
\hline $\begin{array}{l}\text { Any STI } \\
\text { № of participants: } 2232 \\
\text { (3 RCTs) }\end{array}$ & $\begin{array}{l}\text { RR } 0.74 \\
\text { (0.62 to } 0.89)\end{array}$ & $24.9 \%$ & $\begin{array}{l}18.4 \% \\
\text { (15.5 to } 22.2)\end{array}$ & $\begin{array}{l}\text { 6.5\% fewer } \\
\text { ( } 9.5 \text { fewer to } 2.7 \text { fewer) }\end{array}$ & $\begin{array}{l}\oplus \oplus \oplus \mathrm{O}^{-} \\
\text {MODERATE }^{\mathrm{b}}\end{array}$ \\
\hline $\begin{array}{l}\text { Gonorrhoea } \\
\text { № of participants: } 790 \\
\text { (2 RCTs) }\end{array}$ & $\begin{array}{l}\text { RR } 0.59 \\
(0.41 \text { to } 0.86)\end{array}$ & $15.2 \%$ & $\begin{array}{l}9.0 \% \\
(6.2 \text { to } 13.1)\end{array}$ & $\begin{array}{l}\text { 6.2\% fewer } \\
\text { ( } 9 \text { fewer to } 2.1 \text { fewer) }\end{array}$ & $\begin{array}{l}\oplus \oplus \oplus \oplus \\
\mathrm{HIGH}\end{array}$ \\
\hline $\begin{array}{l}\text { Chlamydia } \\
\text { № of participants: } 790 \\
\text { (2 RCTs) }\end{array}$ & $\begin{array}{l}\text { RR } 0.67 \\
\text { (0.47 to } 0.94)\end{array}$ & $16.0 \%$ & $\begin{array}{l}10.7 \% \\
(7.5 \text { to } 15)\end{array}$ & $\begin{array}{l}5.3 \% \text { fewer } \\
\text { (8.5 fewer to } 1 \text { fewer) }\end{array}$ & $\begin{array}{l}\oplus \oplus \oplus \oplus \\
\mathrm{HIGH}\end{array}$ \\
\hline $\begin{array}{l}\text { Trichomonas } \\
\text { № of participants: } 790 \\
\text { (2 RCTs) }\end{array}$ & $\begin{array}{l}\text { RR } 1.01 \\
\text { (0.63 to } 1.60)\end{array}$ & $8.0 \%$ & $\begin{array}{l}8.1 \% \\
(5 \text { to } 12.8)\end{array}$ & $\begin{array}{l}0.1 \% \text { more } \\
\text { ( } 3 \text { fewer to } 4.8 \text { more) }\end{array}$ & $\begin{array}{l}\oplus \oplus \oplus O \\
\text { MODERATE }\end{array}$ \\
\hline $\begin{array}{l}\text { Genital ulcer disease } \\
\text { № of participants: } 457 \\
\text { (1 RCT) }\end{array}$ & RR 4.72 (0.23 to 97.87) & $0.0 \%$ & $\begin{array}{l}0.0 \% \\
(0 \text { to } 0)\end{array}$ & $\begin{array}{l}0.0 \% \text { fewer } \\
\text { (0 fewer to } 0 \text { fewer) }\end{array}$ & $\begin{array}{l}\oplus \oplus \oplus O \\
\text { MODERATE }\end{array}$ \\
\hline
\end{tabular}

Cl Confidence interval; RR: Risk ratio

GRADE Working Group grades of evidence

High certainty: We are very confident that the true effect lies close to that of the estimate of the effect

Moderate certainty: We are moderately confident in the effect estimate: The true effect is likely to be close to the estimate of the effect, but there is a possibility that it is substantially different

Low certainty: Our confidence in the effect estimate is limited: The true effect may be substantially different from the estimate of the effect

Very low certainty: We have very little confidence in the effect estimate: The true effect is likely to be substantially different from the estimate of effect Explanations

ancludes only one study with small sample size and wide confidence intervals

${ }^{\mathrm{b}} \mathrm{High}$ risk of selection bias due to lack of proper randomization in one of the trials 
The certainty of the evidence from studies comparing the Woman's condom to the FC1, and the Wondaleaf condom to the FC2 was judged to be of low mostly due to severe imprecision resulting from the small number of study participants. The certainty of the non-inferiority analysis comparing the functionality of the FC2 to the FC1 and the cupid, cupid 2, Velvet, Woman's, Reddy, Pheonurse, condoms to the FC2 was rated as moderate, downgrading for imprecision.

\section{Agreements and disagreements with other studies or reviews}

Several reviews have attempted to answer our review question [12, 20, 21]. Minnis and colleagues in 2004 reviewed the evidence around the effectiveness of the female condom in preventing STIs from three randomized trial and one prospective cohort study. They reported that results from these studies provide evidence that female condom confer as much protection from STIs as male condom [20]. A review by Gallo et al. in 2013 examined the evidence from randomized and non-randomised studies. They argue that although female condoms (or a combination of female plus male condoms) may provide similar degrees of protection against pregnancy and STIs as do latex male condoms alone, they called for more comparative research to demonstrate this [12]. Vijayakumar and colleagues in 2006 reviewed 137 articles and abstracts (mainly observational studies) on various aspects of female condoms. Based on five randomized trials on effectiveness, the authors concluded that there is limited but convincing evidence that the female condom is effective in increasing protected sex (five studies) and decreasing STI incidence (two studies) among women [21]. Our findings are consistent with theirs. However, our systematic review goes a step further by using GRADE to ascertain the certainty of the evidence. In addition to evaluating the effects of widely marketed condoms, we reviewed the functionality of new female condoms (including the Woman's, Cupid, Pheonurse, Velvet and Reddy,condoms) based on evidence from more recent trials, and found them to be non-inferior when compared to widely marketed ones.

\section{Differences between protocol and review}

There are several differences between the review protocol and the final review [23]. We had planned to include both randomised and non-randomised trials in this review in order to assess the effectiveness, safety and acceptability of the female condom. However, in this review we included only randomised trials used to assess the effectiveness and safety of the female condom. This was due to the large number of studies identified which explored issues around acceptability. This outcome will be addressed in a separate review. Also, we had planned to include trials that compared the female condom to no treatment or other barrier methods for HIV prevention, for example, male condom, microbicides, diaphragm, vaginal sponges and cervical caps. In this review, we also compared the functionality of different types of new female condoms to existing ones using a non-inferiority analysis. Although the non-inferiority analysis and margins were nor prespecified in our protocol, the risk of bias in this non inferiority analysis is low, considering that the non-inferiority margin is already set by the WHO/UNFPA guidelines [18]. Finally, we had planned to assess the possibility of publication bias by constructing a funnel plot but this was not done due to the small number of studies that reported our outcomes of interest.

\section{Potential biases in the review process}

This systematic review was conducted using methods described in the Cochrane Handbook for systematic reviews of interventions [25] and reported in accordance with the Preferred Reporting Items for Systematic Reviews and Meta-Analyses (PRISMA) items [58]. We are not aware of any biases in the review process. We however highlight that a major limitation of included studies is that condom usage is ascertained based on self-reports by study participants. An objective marker of semen exposure would reduce the risk of recall bias [59].

\section{Conclusion}

The use of female and male condoms (when women are given the option to make a choice of one or both at each sexual act) is more effective than use of male condoms only in preventing chlamydia and gonorrhoea and probably more effective in preventing trichomoniasis and other STIs. There may be no difference between male and female condoms in preventing HIV, however, the certainty of the evidence is low and warrants further research. This research is critical considering that the female condom used in the studies that have provided the evidence base for the effectiveness of the female condom in preventing HIV and STI used the FC1 which is no longer in the market. Such studies should be adequately powered and should equally assess acceptability and adverse events. The advent of new female condoms that may be non-inferior to previous and currently marketed ones provide women with more protection options. Although studies suggest that they may be non-inferior to older female condoms, it is equally important for high quality trials to be conducted that assess the effectiveness of these new condoms in the prevention of HIV and STIs. 


\section{Abbreviations}

CENTRAL: Cochrane Central Register of Controlled Trials; FC: Female condom; GRADE: Grading of Recommendations, Assessment, Development and Evaluations; HIV: Human immunodeficiency virus; ICTRP: WHO International Clinical Trials Registry Platform; PATH: Program for Appropriate Technology in Health; STI: Sexually transmitted infections; UNFPA: United Nations Population Fund; USFDA: United States Food and Drug Administration; WHO: World Health Organization

\section{Acknowledgements}

We would like to thank Joy Oliver from Cochrane South Africa for assisting with the search strategy and Dr. Moleen Zunza from the Centre for Evidence Based Health Care for valuable statistical guidance.

\section{Authors' contributions}

AW, RKBM, PM, EJK, and CSW screened the search output for eligible studies, and all five authors reviewed the full text of potentially eligible studies for inclusion, extracted data, assessed the risk of bias, and conducted the analysis. AW and RKB prepared the draft manuscript and all authors contributed important intellectual content, read and approved the final version of the review before submission.

\section{Funding}

This study is funded by the South African Medical Research Council and the National Research Foundation of South Africa grant number 106035. The funders of the study had no role in study design, data collection, data analysis, data interpretation, or writing of the report. The corresponding author had full access to all the data in the study and had the final responsibility for the decision to submit the manuscript for publication.

\section{Availability of data and materials}

The datasets analysed during the current study are publicly available and were obtained by searching PubMed, Cochrane Central Register of Controlled Trials (CENTRAL), EMBASE, WHO International Clinical Trials Registry Platform (ICTRP) and ClinicalTrials.gov.

\section{Ethics approval and consent to participate}

Not applicable.

\section{Consent for publication}

Not applicable.

\section{Competing interests}

The authors declare that they have no competing interests.

\section{Author details}

${ }^{1}$ Cochrane South Africa, South African Medical Research Council, Cape Town, South Africa. ${ }^{2}$ Department of Epidemiology, University of Washington School of Public Health, Seattle, Washington, USA. ${ }^{3}$ Ottumwa Regional Health Center, 1001 Pennsylvania Avenue, Ottumwa, IA 52501, USA. ${ }^{4}$ Grants, Innovation and Product Development, South African Medical Research Council, Cape Town, South Africa. ${ }^{5}$ School of Global Health and Bioethics, Euclid University, Banjul, Gambia. ${ }^{6}$ Division of Epidemiology and Biostatistics, Department of Global Health, Stellenbosch University, Cape Town, South Africa. ${ }^{7}$ Division of Epidemiology and Biostatistics, School of Public Health and Family Medicine, University of Cape Town, Cape Town, South Africa.

Received: 24 October 2019 Accepted: 20 February 2020

Published online: 12 March 2020

\section{References}

1. Unaids. UNAIDS DATA 2018 [Internet]. 2018 [cited 2018 Dec 5]. Available from: http://www.unaids.org/sites/default/files/media_asset/unaids-data-2018_en.pdf.

2. UNAIDS. Putting HIV prevention among adolescent girls and young women on the fast-track and engaging men and boys [Internet]. Geneva. 2016 [cited 2018 Dec 5]. Available from: http://www.unaids.org/sites/default/files/media_asset/ UNAIDS_HIV_prevention_among_adolescent_girls_and_young_women.pdf.

3. Gouws E, Cuchi P. Focusing the HIV response through estimating the major modes of HIV transmission: a multi-country analysis. Sex Transm Infect. 2012;88(Suppl 2):i76-85 [cited 2018 Dec 5] Available from: http://sti.bmj. com/lookup/doi/10.1136/sextrans-2012-050719.
4. Shaw GM, Hunter E. HIV transmission. Cold Spring Harb Perspect Med. 2012; 2(11):a006965 [cited 2018 Dec 5] Available from: http://www.ncbi.nlm.nih. gov/pubmed/23043157.

5. Chun HM, Carpenter RJ, Macalino GE, Crum-Cianflone NF. The Role of Sexually Transmitted Infections in HIV-1 Progression: A Comprehensive Review of the Literature. J Sex Transm Dis. 2013;2013:176459 [cited 2018 Dec 5] Available from: http://www.ncbi.nlm.nih.gov/pubmed/26316953.

6. Lunenfeld B, Van Steirteghem A. Infertility in the third millennium: implications for the individual, family and society: Condensed Meeting Report from the Bertarelli Foundation's Second Global Conference. Hum Reprod Update. 2004; 10(4):317-26 [cited 2018 Dec 5] Available from: https:/academic.oup.com/ humupd/article-lookup/doi/10.1093/humupd/dmh028.

7. Weller SC, Davis-Beaty K. Condom effectiveness in reducing heterosexual HIV transmission. In: Cochrane database of systematic reviews [Internet]; 2002. p. CD003255. [cited 2018 Dec 5] Available from: http://www.ncbi.nlm. nih.gov/pubmed/11869658.

8. Eaton EF, Hoesley CJ. Barrier Methods for Human Immunodeficiency Virus Prevention. Infect Dis Clin North Am. 2014;28(4):585-99 [cited 2018 Dec 5] Available from: https://www.sciencedirect.com/science/article/pii/S0891552 014000592?via\%3Dihub.

9. Chimbiri AM. The condom is an 'intruder' in marriage: Evidence from rural Malawi. Soc Sci Med. 2007;64(5):1102-15 [cited 2018 Dec 5] Available from: http://www.ncbi.nlm.nih.gov/pubmed/17240504.

10. Maswanya ES, Moji K, Aoyagi K, Takemoto T. Sexual behavior and condom use in female students in Dar-es-Salaam, Tanzania: differences by steady and casual partners. East Afr J Public Health. 2011;8, 69(2):-76 [cited 2018 Dec 5] Available from: http://www.ncbi.nlm.nih.gov/pubmed/22066289.

11. Gollub EL. The female condom: tool for women's empowerment. Am J Public Health. 2000;90(9):1377-81 [cited 2018 Dec 5] Available from: http:// www.ncbi.nlm.nih.gov/pubmed/10983187.

12. Gallo MF, Kilbourne-Brook M, Coffey PS. A review of the effectiveness and acceptability of the female condom for dual protection. Sex Health. 2012; 9(1):18-26.

13. Gallo MF, Norris AH, Turner AN. Female condoms: New choices, old questions. Lancet Glob Heal. 2013;1(3):E119-20 [cited 2019 Jan 10] Available from: http://www.embase.com/search/results?subaction=viewrecord\&from= export\&id=L370273287.

14. UNFPA - United Nations Population Fund. Prequalification Programme for Female Condoms [cited 2018 Dec 8]. Available from: https://www.unfpa. org/resources/prequalification-programme-female-condoms.

15. Beksinska M, Smit J, Joanis C, Potter W. New female condoms in the pipeline. Reprod Health Matters. 2012;20(40):188-96 [cited 2018 May 23] Available from: https://www.tandfonline.com/doi/full/10.1016/S0968-8080\%2812\%2940659-0.

16. Moore L, Beksinska M, Rumphs A, Festin M, Gollub EL. Knowledge, attitudes, practices and behaviors associated with female condoms in developing countries: a scoping review. Open Access J Contracept. 2015;6:125-42.

17. Beksinska M, Smit J, Joanis C, Potter W. New female condoms in the pipeline. Reprod Health Matters. 2012;20(40):188-96 [cited 2018 Dec 5] Available from: https://www.tandfonline.com/doi/full/10.1016/S0968-8080\%2 812\%2940659-0

18. WHO, UNAIDS, UNFPA, International FH. Female Condom: Generic Specification, Prequalification and Guidelines for Procurement, 2012 [Internet]. [cited 2018 Dec 8]. Available from: https://www.unfpa.org/sites/ default/files/resource-pdf/Female Condom Generic Specification EN_1.pdf.

19. Drew WL, Blair M, Miner RC, Conant M. Evaluation of the virus permeability of a new condom for women. Sex Transm Dis. 1990;17(2):110-2 [cited 2018 Nov 12]Available from: http://www.ncbi.nlm.nih.gov/pubmed/2163113.

20. Minnis AM, Padian NS. Effectiveness of female controlled barrier methods in preventing sexually transmitted infections and HIV: Current evidence and future research directions. Sex Transm Infect. 2005;81(3):193-200 [cited 2018 Mar 9] Available from: http://www.embase.com/search/results?subaction= viewrecord\&from $=$ export\&id $=\llcorner 40835042$.

21. Vijayakumar G, Mabude Z, Smit J, Beksinska M, Lurie M. A review of femalecondom effectiveness: Patterns of use and impact on protected sex acts and STI incidence. Int J STD AIDS. 2006;17(10):652-9 [cited 2018 May 23] Available from: http://www.embase.com/search/results?subaction= viewrecord\&from=export\&id=L44611145.

22. Food and Drug Administration, HHS. Obstetrical and Gynecological Devices; Reclassification of Single-Use Female Condom, To Be Renamed Single-Use Internal Condom. Final order. Fed Regist. 2018;83(188):48711-3 [cited 2018 Nov 19] Available from: http://www.ncbi.nlm.nih.gov/pubmed/30272398. 
23. Mome RK, Wiyeh AB, Kongnyuy EJ, Wiysonge CS. Effectiveness of female condom in preventing HIV and sexually transmitted infections: a systematic review protocol. BMJ Open. 2018;8(8):e023055 [cited 2019 Jan 2] Available from: http://www.ncbi.nlm.nih.gov/pubmed/30082362

24. Beksinska M, Joanis C, Manning J, Smit J, Callahan M, Deperthes B, et al. Standardized definitions of failure modes for female condoms;10017. [cited 2018 Nov 10] Available from: https://www.contraceptionjournal.org/article/ S0010-7824(06)00387-8/pdf.

25. Higgins J, Green S. Cochrane Handbook for systematic reviews of interventions version 5.1.0 [updated March 2011] [Internet]. The Cochrane Collaboration. The Cochrane Collaboration; 2011. Available from: http:// handbook.cochrane.org.

26. Guyatt GH, Oxman AD, Vist GE, Kunz R, Falck-Ytter Y, Alonso-Coello P, et al, GRADE: an emerging consensus on rating quality of evidence and strength of recommendations. BMJ. 2008;336(7650):924-6 [cited 2018 Jan 18] Available from: http://www.ncbi.nlm.nih.gov/pubmed/18436948.

27. Treadwell J, Uhl S, Tipton K, Singh S, Santaguida L, Sun X, et al. Assessing Equivalence and Noninferiority [Internet]. Assessing Equivalence and Noninferiority. US: Agency for Healthcare Research and Quality; 2012. [Cited 2019 mar 19]Available from: http://www.ncbi.nlm.nih.gov/pubmed/22834031.

28. Prostate Specific Antigen (PSA) and Acute Failure Modes Study of the PATH Woman's Condom and FC2 Female Condom - Tabular View - ClinicalTrials. gov [Internet]. [cited 2019 Mar 21]. Available from: https://clinicaltrials.gov/ ct2/show/record/NCT01178840?term=female+condom\&rank=4.

29. Fontanet AL, Saba J, Chandelying V, Sakondhavat C, Bhiraleus P, Rugpao S, et al. Protection against sexually transmitted diseases by granting sex workers in Thailand the choice of using the male or female condom: Results from a randomized controlled trial. AIDS. 1998;12(14 CC-Fertility Regulation CC-HIV/AIDS CC-Work CC-Sexually Transmitted Infections):18519 Available from: http://www.embase.com/search/results?subaction= viewrecord\&from=export\&id=L28454451.

30. Feldblum PJ, Kuyoh MA, Bwayo JJ, Omari M, Wong EL, Tweedy KG, et al. Female condom introduction and sexually transmitted infection prevalence: results of a community intervention trial in Kenya. AIDS. 2001;15(8):1037-44 Available from: http://www.embase.com/search/results?subaction= viewrecord\&from=export\&id=L32476671.

31. Galvão LW, Oliveira LC, Díaz J, Kim DJ, Marchi N, Van Dam J, et al. Effectiveness of female and male condoms in preventing exposure to semen during vaginal intercourse: A randomized trial. Contraception. 2005; 71(2):130-6 [cited 2018 Nov 8] Available from: http://www.ncbi.nlm.nih.gov/ pubmed/15707563.

32. Macaluso M, Blackwell R, Jamieson DJ, Kulczycki A, Chen MP, Akers R, et al. Efficacy of the Male Latex Condom and of the Female Polyurethane Condom as Barriers to Semen during Intercourse: A Randomized Clinical Trial. Am J Epidemiol. 2007;166(1):88-96 [cited 2018 mar 9] Available from: http://www.ncbi.nlm.nih.gov/pubmed/17420182.

33. Beksinska M, Smit J, Mabude Z, Vijayakumar G, Joanis C, et al. Performance of the Reality polyurethane female condom and a synthetic latex prototype: a randomized crossover trial among South African women. Contraception. 2006;73(4 CC-HS-FERTILREG CC-Fertility Regulation CC-HIV/AIDS CC-HSHANDSRCH):386-393. Available from: https://www.cochranelibrary.com/ central/doi/10.1002/central/CN-00563227/full.

34. Beksinska ME, Piaggio G, Smit JA, Wu J, Zhang Y, Pienaar J, et al. Performance and safety of the second-generation female condom (FC2) versus the Woman's, the VA worn-of-women, and the Cupid female condoms: a randomised controlled non-inferiority crossover trial. Lancet Glob Heal. 2013;1(3):e146-52 [cited 2018 May 23] Available from: https:// www.sciencedirect.com/science/article/pii/S2214109X13700548.

35. Beksinska M, Greener R, Kleinschmidt I, Pillay L, Maphumulo V, Smit J. A randomized noninferiority crossover controlled trial of the functional performance and safety of new female condoms: an evaluation of the velvet, Cupid2, and FC2. Contraception. 2015;92(3):261-7. Available from:. https://doi.org/10.1016/j.contraception.2015.05.008.

36. Beksinska ME, Mphili N, Greener R. A functional performance study of the "Wondaleaf" female condom. AIDS. 2018;2018:305.

37. Hou L-Y, Qiu H-Y, Zhao Y-Z, Zeng X-S, Cheng Y-M. A crossover comparison of two types of female condom. Int J Gynaecol Obstet. 2010;108(3):214-8.

38. Joanis C, Beksinska M, Hart C, Tweedy K, Linda J, Smit J. Three new female condoms: Which do South-African women prefer? Contraception. 2011; 83(3):248-54 [cited 2018 Nov 8] Available from: http://www.ncbi.nlm.nih. gov/pubmed/21310287.
39. Schwartz JL, Barnhart K, Creinin MD, Poindexter A, Wheeless A, KilbourneBrook M, et al. Comparative crossover study of the PATH Woman's Condom and the FC Female Condom ${ }^{\circledast}$. Contraception. 2008;78(6):465-73 [cited 2018 Nov 8] Available from: http://www.ncbi.n/m.nih.gov/pubmed/19014792.

40. French PPP, Latka M, Gollub ELL, Rogers C, Hoover DRR, Stein ZAA, et al. Use-effectiveness of the female versus male condom in preventing sexually transmitted disease in women. Sex Transm Dis. 2003;30(5):433-9 Available from: http://www.embase.com/search/results?subaction=viewrecord\&from= export\&id=L36605493.

41. Ray S, van De Wijgert J, Mason P, Ndowa F, Maposhere C, et al. Constraints faced by sex workers in use of female and male condoms for safer sex in urban zimbabwe. J Urban Heal. 2001;78(4):581-92 Available from: https:// www.cochranelibrary.com/central/doi/10.1002/central/CN-00404745/full.

42. Gollub E, Cyrus-Cameron E, Armstrong K, Boney T, Mercer D, Fiore D, et al. Active drug-using women use female-initiated barrier methods to reduce HIV/STI risk: results from a randomized trial. ISRN Addict. 2013;2013:768258.

43. A.M. N, M. L, N. VN, T. W, R. F. Female condom functionality in the presence of a vaginal ring. Top Antivir Med [Internet]. 2015;23:457. Available from: http://www.embase.com/search/results?subaction=viewrecord\&from= export\&id=L72119889.

44. Collins PY, von Unger $H$, Putnins S, Crawford N, Dutt R, Hoffer $M$, et al. Adding the female condom to HIV prevention interventions for women with severe mental illness: a pilot test. Commun Ment Health J. 2011;47(2): 143-55 Available from: https://www.cochranelibrary.com/central/doi/10.1 002/central/CN-00780098/full.

45. Beksinska M, Greener R, Mphili N, Smit J, Kilbourne-Brook M, Coffey PS. Functional performance study of an adapted design of the woman's condom: a crossover, noninferiority, randomized clinical trial. Eur J Contracept Reprod Heal Care. 2019;24(3):233-9.

46. Cheng Y. China female condom (FCc) functionality study against an equivalent marketed female condom (FC2). Fertil Steril. 2019;112(3):e308.

47. Macaluso M, Demand M, Artz L, Fleenor M, Robey L, Kelaghan J, et al. Female condom use among women at high risk of sexually transmitted disease. Fam Plan Perspect. 2000;32(3):138-44.

48. Soper D, Shoupe D, Shangold G, Shangold M, Gutmann J, Mercer L. Prevention of vaginal trichomoniasis by compliant use of the female condom. Sex Transm Dis. 1993;20(3):137-9 Available from: http://www.embase.com/search/ results?subaction=viewrecord\&from $=$ export\&id $=\mathrm{L} 23179822$.

49. Macaluso M, Artz L, Kelaghan J, Austin H, Fleenor M, Hook EW. Prospective study of barrier contraception for the prevention of sexually transmitted diseases: study design and general characteristics of the study group. Sex Transm Dis. 1999;26(3):127-36.

50. Beksinska M, Smit J, Mphili N, Greener R, Maphumulo V. The panty condom: a pilot study of the function and acceptability of an alternative female condom design. Int J STD AIDS. 2019;30(11):1080-6.

51. Ting RS-K, Wong EL, Tnay JK-S. A pilot study on the functional performance and acceptability of an innovative female condom (Wondaleaf ${ }^{\text {\&reg; }}$ ) in Malaysia. Open Access J Contracept. 2018;9:11-20.

52. Hardwick D. The effectiveness of a female condom intervention on women's use of condoms. Can J Hum Sex. 2002;11(2):63-76 14p. Available from: http:// ezproxy.twu.edu:2048/login?url=http://search.ebscohost.com/login. aspx?direct=true\&db=ccm\&AN=106876321\&site=ehost-live\&scope=site.

53. Weir SS, Roddy RE, Zekeng L, Ryan K. Association between condom use and HIV infection: a randomised study of self reported condom use measures. J Epidemiol Commun Health. 1999;53:417-22 Available from: http://www.embase.com/search/results?subaction=viewrecord\&from= export\&id $=\mathrm{L} 29306616$

54. Gollub EL, French P, Latka M, Rogers C, Stein Z. Achieving safer sex with choice: studying a women's sexual risk reduction hierarchy in an STD clinic. I Womens Health Gend Based Med. 2001;10(8 CC-Consumers and Communication):771-83 Available from: https://www.cochranelibrary.com/ central/doi/10.1002/central/CN-00456363/full.

55. Musaba E, Morrison CS, Sunkutu MR, Wong EL. Long-term use of the female condom among couples at high risk of human immunodeficiency virus infection in Zambia. Sex Transm Dis. 1998;25(5):260-4.

56. Farr G, Gabelnick H, Sturgen K, Dorflinger L. Contraceptive efficacy and acceptability of the female condom. Am J Public Health. 1994;84(12):1960-4.

57. Steiner M, Trussell J, Glover L, Joanis C, Spruyt A, Dorflinger L. Standardized protocols for condom breakage and slippage trials: a proposal. Am J Public Health. 1994:84(12):1897-900 [cited 2019 Jan 10] Available from: http:// www.ncbi.nlm.nih.gov/pubmed/7998626. 
58. Liberati A, Altman DG, Tetzlaff J, Mulrow C, Gøtzsche PC, loannidis JPA, et al. The PRISMA Statement for Reporting Systematic Reviews and Meta-Analyses of Studies That Evaluate Health Care Interventions: Explanation and Elaboration. PLoS Med. 2009;6(7):e1000100. [cited 2018 Mar 9] Available from: https://doi.org/10.1371/journal.pmed.1000100.

59. Walsh TL, Snead MC, St. Claire BJ, Schwartz JL, Mauck CK, Frezieres RG, et al. Comparison of self-reported female condom failure and biomarkerconfirmed semen exposure. Contraception. 2019;100(5):406-12.

\section{Publisher's Note}

Springer Nature remains neutral with regard to jurisdictional claims in published maps and institutional affiliations.

- fast, convenient online submission

- thorough peer review by experienced researchers in your field

- rapid publication on acceptance

- support for research data, including large and complex data types

- gold Open Access which fosters wider collaboration and increased citations

- maximum visibility for your research: over $100 \mathrm{M}$ website views per year

At $\mathrm{BMC}$, research is always in progress. 